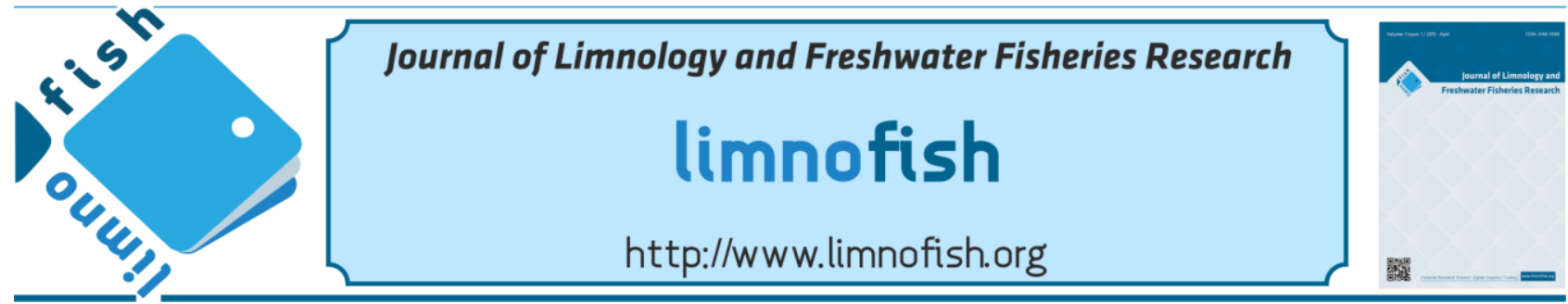

\title{
Aksu Çayı-Köprüçay Nehri (Isparta-Türkiye) Cobitis turcica (Hanko, 1925) Populasyonunda Yaş, Büyüme ve Ölüm Oranları
}

\author{
Habil Uğur KOCA*, Murtaza ÖLMEZ \\ Süleyman Demirel Üniversitesi, Eğirdir Su Ürünleri Fakültesi, Isparta, Türkiye
}

\section{$\ddot{O} z$}

$\mathrm{Bu}$ çalıșmada, Aksu Çay1-Köprüçay Nehri (Isparta-Türkiye)'nin endemik türü olan Cobitis turcica (Hanko, 1925) populasyonunun yaş, büyüme ve ölüm oranları incelenmiştir. $C$. turcica populasyonu I-V yaş arasında dağ 1 lım göstermiş, ortalama total boy $81,1 \pm 0,15 \mathrm{~mm}$, ortalama ağırlık $5,68 \pm 0,17 \mathrm{~g}$ bulunmuştur. Boy-ağırlık ilişkisi $W=0,14 T L^{2,95}$ boy ve ağırlıkça von Bertalanffy büyüme denklemi $L_{t}=138\left[1-e^{-0,24(t+0,83)}\right]$ ve $W_{t}=19,5\left[1-e^{-0,24(t+0,83)}\right]^{2,95}$, yaşama oranı $(S) 0,71$, ölüm oranı $(A) 0,29$ olarak hesaplanmıştır.

Anahtar kelimeler: Cobitis turcica, endemik balık, yaş-büyüme-ölüm, Aksu Çay1-Köprüçay Nehri
MAKALE BILGISI

ARAŞTIRMA MAKALESi
$\begin{array}{ll}\text { Geliş } & : 03.07 .2015 \\ \text { Düzeltme } & : 09.11 .2015 \\ \text { Kabul } & : 04.12 .2015 \\ \text { Yayım } & : 20.12 .2015\end{array}$

DOI: $10.17216 /$ LimnoFish-5000128870

\section{* SORUMLU YAZAR}

hukoca@gmail.com

Tel : +902462118624

Faks: +902462118697

\section{Age, Growth and Mortality of the Cobitis turcica (Hanko, 1925) Population from Aksu Stream-Köprüçay River} (Isparta-Turkey)

\begin{abstract}
In this study, age, growth and mortality characteristics of endemic species Cobitis turcica (Hanko, 1925) from the Aksu Stream-Köprüçay River (Isparta-Turkey) were investigated. The age frequency of $C$. turcica was between I-V. Average fork length, average weight, length-weight relationship, length and weight von Bertalanffy growth formula, survival ratio (S) the mortality ratio (A) were found as $81.1 \pm 0.15 \mathrm{~mm}, 5.68 \pm 0.17 \mathrm{~g}, W=0.14 T L^{2.95}, L_{t}=138\left[1-e^{-0.24(t+0.83)}\right]$ and $W_{t}=19.5\left[1-e^{-0.24(t+0.83)}\right]^{2.95}$, and $0.71,0.29$, respectively.
\end{abstract}

Keywords: Cobitis turcica, endemic fish, age-growth-mortality, Aksu Stream-Köprüçay River

Koca HU, Ölmez M. 2015. Aksu Çayı-Köprüçay Nehri (Isparta-Türkiye) Cobitis turcica (Hanko, 1925) Populasyonunda Yaş, Büyüme ve Ölüm Oranlar1. LimnoFish. 1(3):113-121. doi: 10.17216/LimnoFish-5000128870

\section{Giriş}

Üç kıtanın birleştiği, doğal kaynaklar bakımından zengin Akdeniz havzasında yer alan 19 ülkede 253 endemik balık taksonu bulunduğu belirlenmiştir. $\mathrm{Bu}$ taksonlardan \%3'ünün soyu tükenmiş, $\% 56$ 'sının tehdit altında, \%18'inin kritik düzeyde, $\% 18$ 'inin yüksek risk altında, \%20'sinin duyarlı ve sadece \%20'sinin en az tehlikede olduğu açıklanmıştır. Tatlısu balık faunası açısından oldukça zengin kaynaklara sahip Türkiye'de ise yapılan bir çalıșmada Akdeniz ve Ege havzalarındaki iç sularda yayılış gösteren 34 endemik balık taksonu (Smith ve Darwall 2006), başka bir çalışmada ise 300 tür ve bu türlerden de en az 54'ünün endemik olduğu bildirilmiştir (Froese ve Pauly 2013).

Cobitis genusu 77 tür ile temsil edilir (Froese ve Pauly 2013) ve Türkiye'de bulunan 14 türün birçoğu endemiktir (Erk'akan vd. 2008). Bu endemik türlerden biri olan $C$. turcica, çalışma sahamız olan Aksu Çayı-Köprüçay Nehri (Isparta-Türkiye)'nin Ayvalıpınar-Bağıllı Köyü (Eğirdir) arasında ve bu köy yakınlarındaki toprak kanallarda, akarsuyun yavaş aktığı tabanı çamur ve kumlu kesimlerinde yoğun olarak bulunan bir türdür. Üreme dönemi haziran ile temmuz ayları arasındadır. Vücut hafif yanlardan yassılaşmış ve uzun yapılıdır. Başta bulunan dikenin ucu çatalsızdır. Ağız alt 
durumlu ve çevresinde kısa üç çift bıyık bulunur. Vücut rengi çok değişken olmakla beraber sırtı sarıms1-gri, yan taraflar ve karın kısmı ise bazen beyaz bazen de kirli sarıdır.

C. turcica, kuraklık, su kirliliği, istilacı türlerin baskısı ve insan kaynaklı habitatlarının bozulmasından çok fazla etkilenir. Bu yüzden 2006 yılında IUCN tarafindan nesli tükenmekte olan türler kategorisine dahil edilmiştir (Crivelli 2006). Dolayisıyla Cobitis cinsine ait türlerin kaynaklarımızdaki populasyon yapılarının ortaya konmas1 gerekmektedir. Son yillarda yapilan çalışmalarla beslenme (Juchno ve Boron 2006; Bohlen 2008), taksonomi (Coad 1988; Yeğen vd. 2007; Freyhof vd. 2008), habitat (Bohlen 2002; Yeğen 2009; Erk'akan vd. 2013; Kırankaya ve Ekmekçi 2014), genetik (Mousavi-Sabet vd. 2012; Erk'akan vd. 2013) ve biyomas (Nunn vd. 2003) değerleri ortaya çıkarılmıştır.

$\mathrm{Bu}$ çalışmada ise $C$. turcica türünün yaş, büyüme ve ölüm oranı bilgileri saptanarak olası koruma stratejilerinin geliştirilmesine yardımcı olmak amaçlanmıştır.

\section{Materyal ve Metot}

Toplam uzunluğu $156 \mathrm{~km}$ olan Aksu Çay1Köprüçay Nehri Akdeniz Bölgesi'nde, Isparta İli Aksu İlçesinin kuzeybatısındaki Anamas Dağları'nın güneyinden doğar ve Serik İlçesinin doğusunda Dipsiz mevkii yakınlarından geniş bir nehir ağzı ile Akdeniz'e dökülür. Araştırma sahası olarak Aksu Çayı-Köprüçay Nehri'nin Isparta ili sınırlarında kalan 82 km'lik kısmında belirlenen 6 istasyon seçilmiş, üçüncü, dördüncü ve beşinci istasyonlarda C. turcica yakalanmıştır. (Kasımlar Köprüsü: $37^{\circ} 31^{\prime} 08^{\prime \prime} \mathrm{N}$ ve $031^{\circ} 12^{\prime} 00^{\prime \prime} \mathrm{E}$ [1. İstasyon]; İncedere Köprüsü: $37^{\circ} \quad 34^{\prime} \quad 57^{\prime \prime} \mathrm{N}$ ve $031^{\circ} \quad 10^{\prime} \quad 31^{\prime \prime} \mathrm{E}$ [2. İstasyon]; Karacahisar Köprüsü: $37^{\circ} 37^{\prime} 00^{\prime \prime} \mathrm{N}$ ve $031^{\circ} 10^{\prime} 17^{\prime \prime} \mathrm{E}$ [3. İstasyon]; Ayvalıpınar Mevki: $37^{\circ} 39^{\prime} 28^{\prime \prime} \mathrm{N}$ ve $031^{\circ} 03$ ' $58^{\prime \prime} \mathrm{E}$ [4. İstasyon]; Asak Köprüsü: $37^{\circ} \quad 44^{\prime} \quad 58^{\prime \prime} \mathrm{N}$ ve $031^{\circ} 01^{\prime} \quad 50^{\prime \prime} \mathrm{E}$ [5. İstasyon]; Başpınar Kaynağı: $37^{\circ} 49^{\prime} 43^{\prime \prime} \mathrm{N}$ ve $031^{\circ} 06^{\prime} 37^{\prime \prime} \mathrm{E}$ [6. İstasyon]) (Şekil 1).

C. turcica türünün yakalanamadığı istasyonların ortak özelliği zemin yapılarının iri taşlık, kayalık ve çakıllı olması aynı zamanda akıntı hızının da fazla olmasıdır. Yakalandığı üçüncü, dördüncü ve beşinci istasyonların ise zemin yapıları kumlu ve milli, kıyısal bölge yer yer ağaçlık ve çalılık yapılı, akıntı hızı da yavaştır. Belirtilen istasyonlarda yakalanan C. turcica bireylerine ait yaş, büyüme ve ölüm oranlarına ilişkin farklılıklar istatistiksel olarak önemsiz bulunmuştur $(p>0,05)$.

Aksu Çay1-Köprüçay Nehri'nde Mart 2009Şubat 2010 tarihleri arasında aylık periyotlarda ve ayda bir defa yürütülen araştırmada, 258 adet C. turcica bireyi yakalanmıştır (Şekil 2).

Balık örnekleri 220 volt ve 650 watt gücünde alternatif akımla çalışan, sap kısmı $120 \mathrm{~cm}$ uzunluğunda, $23 \mathrm{~cm}$ çaplı anot ve katottan oluşan elektroşok cihazı ile avlanmıştır (Seber 1982). Balık boyları milimetrik taksimatlı ölçüm tahtası ile ölçülmüş, ağırlıkları ise arazi tipi $0,01 \mathrm{~g}$ hasssiyette elektronik terazi ile tartılmıştır. Yaş tespiti Lagler (1956)'ya göre pullardan yapılmıştır.

Yaş grupları arasındaki boy ve ağırlık artışlarının hesaplanmasinda;

$$
\begin{aligned}
M B & =L_{t}-L_{t-1}, \\
M B & =W_{t}-W_{t-1}, \\
O B & =\left[\left(L_{t}-L_{t-1}\right) /\left(L_{t-1}\right)\right] 100, \\
O B & =\left[\left(W_{t}-W_{t-1}\right) /\left(W_{t-1}\right)\right] 100, \\
A B & =\left[\left(\log _{e} L_{t}-\log _{e} L_{t-1}\right)\right] /\left(\Delta_{t}\right), \\
A B & =\left[\left(\log _{e} W_{t}-\log _{e} W_{t-1}\right)\right] /\left(\Delta_{t}\right)
\end{aligned}
$$

Eşitlikleri kullanılmıştır (Ricker 1975). Eşitliklerdeki, $M B$ : mutlak büyüme, $O B$ : oransal büyüme, $A B$ : anlık büyüme, $L_{t}: \mathrm{t}$ yaş grubundaki balıkların ortalama boyu $(T L ; \mathrm{mm}), L_{t-1}: \mathrm{t}-1$ yaş grubundaki balıkların ortalama boyu (TL;mm), $W_{t}: t$ yaş grubundaki balıkların ortalama ağırlığı $(\mathrm{g})$, $W_{t-1}: t-1$ yaş grubundaki balıkların ortalama ağırlığı (g)'dir.

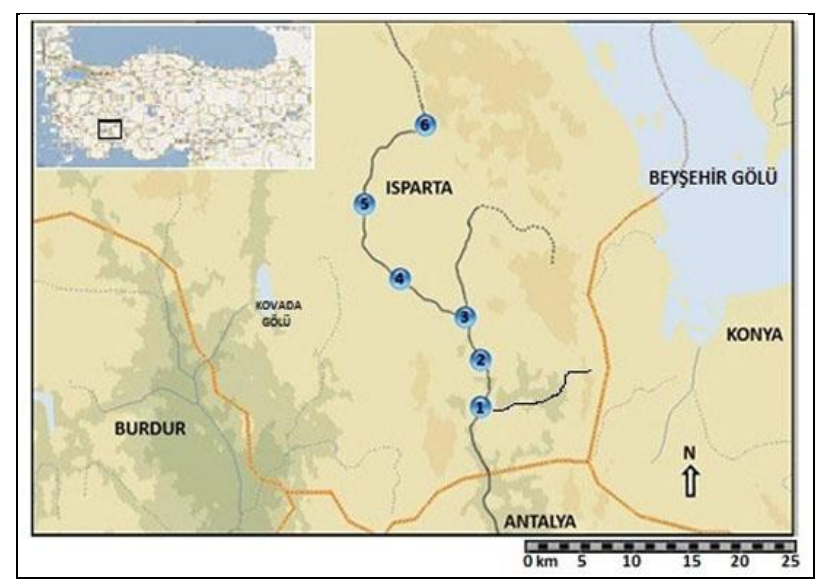

Şekil 1. Araştırma alanı ve araştırma istasyonları.

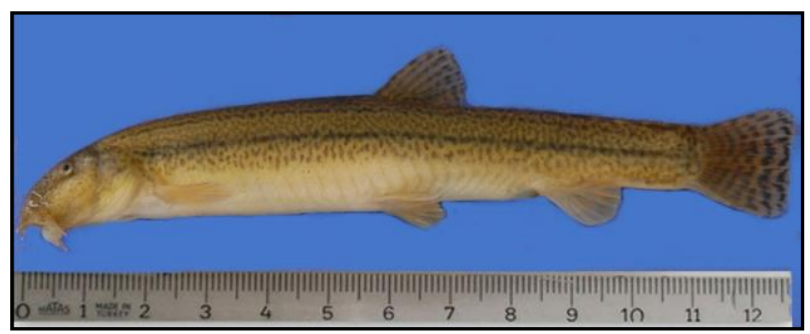

Şekil 2. Cobitis turcica (Hanko, 1925) (Orijinal). 
Örneklenen balıklarda total boy ile total ağırlık arasındaki ilişkinin hesaplanmasında

$$
W=a L^{b}
$$

eşitliği kullanılmıştır (Ricker 1975). Eşitlikte, $a$ : doğrunun " $y$ " eksenini kestiği nokta, $b$ : doğrunun eğimini gösteren katsayıdır. Fulton kondisyon faktörünün hesaplanmasında

$$
K F=\left(W / L^{3}\right) 100
$$

eşitliğinden yararlanılmıştır (Ricker 1975).

Yaşama ve ölüm oranı ile anlık toplam ölüm katsayısı Heincke yöntemi ile hesaplanmış, avlanabilir populasyona katılan en genç yaş grubunun doğru olarak seçilip seçilmediği Chapman-Robson yöntemindeki Ki-kare testiyle kontrol edilmiştir (Ricker 1975). Yaşama oranı:

$S=\left(\Sigma N-N_{0}\right) /(\Sigma N)$,

Anlık ölüm katsayısı:

$Z=-\log _{e} S$

eşitlikleri ile hesaplanmıştır. Doğal ölüm katsayısı $(M)$, von Bertalanffy büyüme denklemi parametreleri ve ortalama su sıcaklığı değerleri kullanılarak;

$\log M=-0,0066-0,279 \log L_{\infty}+0,6543 \log k+0,4634 \log T$

eşitliğinde hesaplanmıştır. Avcılık ölüm katsayısı:

$F=Z-M$,

ölüm oranı:

$A=1-S$,

ölüm oranının iki bileşeninin hesaplanmasında ise;

$A=u+v$,

$u=F A / Z$,

$v=M A / Z$

eşitlikleri kullanılmıştır (Sparre vd. 1989; Erkoyuncu 1995). Eşitliklerde, $N$ : örnek büyüklügü, $\quad N_{0}$ : populasyona tam olarak katılımın en fazla olduğu yaş grubu, $L_{\infty}$ ve $k$ : von Bertalanffy eşitliği parametreleri, $T$ : habitatın yüzey suyu sıcaklığının yıllık ortalaması, $u$ : avlanmadan ileri gelen ölüm beklentisi, $v$ : doğal ölüm beklentisidir.

Hidrolojik verilerden akıntı hızı, suda yüzen cismin 5 m'lik mesafeyi alması için geçen sürenin ölçülmesi, debi ise yüzdürme-enine kesit metoduyla (Atay 1995) hesaplanmıştır. Fizikokimyasal değerler; sıcaklık ve elektrik iletkenliği taşınabilir YSI 300 S-C-T metre, çözünmüş oksijen taşınabilir WTW OXI 320 oksijenmetre, $\mathrm{pH}$ ise taşınabilir WTW pH 330-İ pH metre ile ölçülmüştür.

Araştırmada yakalanan balık türlerinin çeşitli özelliklerine ilişkin bütün istatistiki hesaplamalar, karşılaştırmalar ve kontrollerde Düzgüneş vd. (1983) ile Yurtsever (1984)'den yararlanılmış, önem seviyesi olarak $(p)$ 0,05 kullanılmıştır.

\section{Bulgular}

Mart 2009-Şubat 2010 tarihleri arasındaki bir yıllık sürede yürütülen çalışmada su sıcaklığ 1 $12,51 \pm 0,55 \quad{ }^{\circ} \mathrm{C}$, çözünmüş oksijen miktarı $11,39 \pm 0,11 \mathrm{mg} / 1, \mathrm{pH} 8,51 \pm 0,03$ ve elektrik iletkenliği $356,89 \pm 3,20 \mu \mathrm{mhos} / \mathrm{cm}$ olarak tespit edilmiştir. Yine

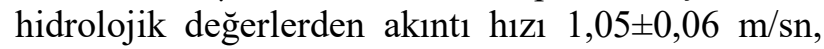
debi ise $6,79 \pm 0,651 /$ sn şeklinde saptanmıştır.

Toplam 258 birey üzerinde yapılan $C$. turcica populasyondaki bireylerin I-V yaş arasında dağılım gösterdiği, I yaş grubunun baskın olduğu $(\% 22,09)$, bu yaş grubunu II yaş grubunun $(\% 21,71)$ izlediği tespit edilmiştir (Şekil 3).

C. turcica populasyonundan elde edilen örneklerde boy dağılımı 48,0-123,0 $\mathrm{mm}$ arasında değişirken ortalama boy $81,1 \pm 0,15 \mathrm{~mm}$ olarak bulunmuştur. Populasyonun \%25,97'si 48,0-55,5 $\mathrm{mm}$ arasındaki bireylerden oluşurken balıkların \%89,92'si 48,0-101,1 mm boy aralığında tespit edilmiştir. Stoğun çoğunluğunu oluşturan 48,0-61,1 mm arasındaki bireyler I yaş grubu içinde yer almaktadir.

C. turcica türünün yaş gruplarına göre ortalama total boyları I. yaştan itibaren sırasıyla; $51,1 \pm 0,04 \mathrm{~mm}, 68,8 \pm 0,11 \mathrm{~mm}, 84,7 \pm 0,06 \mathrm{~mm}$, $96,5 \pm 0,04 \mathrm{~mm}$ ve $103,8 \pm 0,05 \mathrm{~mm}$ olarak saptanmıştır (Çizelge 1). Yine söz konusu populasyonunun boyca büyüme denklemi ve eğrisi Şekil 4'de verilmiştir.

C. turcica bireylerinde minimum ağırlık $1,20 \mathrm{~g}$, maksimum ağırlık 14,32 g, ortalama ağırlık ise 5,68 $\pm 0,17 \mathrm{~g}$ bulunmuştur.

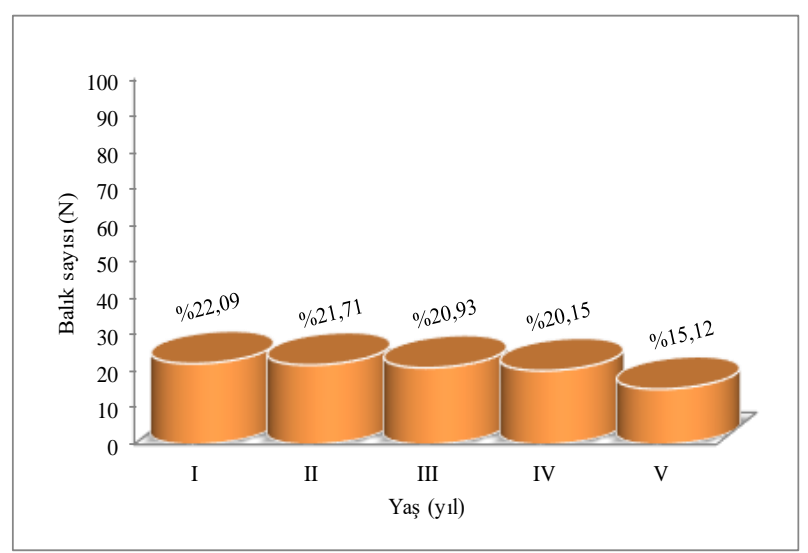

Şekil 3. C. turcica populasyonunun yaş kompozisyonu. 
1,20-2,51 g arasındaki bireyler populasyonun $\% 23,64$ 'ünü oluşturmuştur. Populasyondaki balıkların ağırlığ 1,20-7,79 g arasında yoğunlaşmış olup, balıkların \%84,49’u bu ağırlık aralığında bulunmuştur. Yaş gruplarına göre ortalama ağırlıkları I. yaştan itibaren sırasıyla; $1,85 \pm 0,11 \mathrm{~g}, 3,92 \pm 0,07 \mathrm{~g}$, $5,87 \pm 0,06 \mathrm{~g}, 7.54 \pm 0,21 \mathrm{~g}$ ve $8.95 \pm 0,16$ g olarak saptanmıştır (Çizelge 2). C. turcica populasyonunun ağırlıkça büyüme denklemi ve eğrisi ise Şekil 5'de verilmiştir.

C. turcica türünün bireysel boy ve ağırlıklarından hesaplanan boy-ağırlık ilişkisi $W=0,14 T L^{2,95}(r=0,94)$ olarak bulunmuştur (Şekil 6). " $b$ ” değeri 2,95 olarak hesaplanmış, değerin 3'ten önemli bir sapma göstermediği tespit edilmiştir ( $\mathrm{t}$ testi, $p>0,05$ ). Türün boy-ağırlık ilişkisindeki " $b$ ” değerine göre negatif allometrik büyüme gösterdiği belirlenmiştir.

Araştırma sonucu elde edilen verilerden hesaplanan yaşlara göre mutlak, oransal ve anlık büyüme değerleri Çizelge 3'de verilmiştir. C. turcica bireylerinde en yüksek artış I. yaştan II. yaşa geçişte hesaplanmıştır. Diğer gruplarda ise yaş artışına bağlı olarak artışın azaldığ 1 anlaşılmaktadır.

Yaş artışı ile birlikte kondisyon faktörlerinin de azaldığı tespit edilen populasyonda kondisyon faktörü I yaşında en yüksek değerde $(1,37 \pm 0,09)$ olup, V. yaşta $0,80 \pm 0,01$ 'e düşmüştür. Populasyon için ortalama kondisyon faktörü ise $1,04 \pm 0,02$ olmuştur (Çizelge 4).

Çizelge 1. C. turcica populasyonunun yaş-boy ilişkisi [TL:Total boy (mm); $S E$ :Standart hata].

\begin{tabular}{cccc}
\hline Yaş grubu & $T L \pm S E$ (min-mak) & $\begin{array}{c}\text { von Bertalanffy ile } \\
\text { hesaplanan }\end{array}$ & t-testi $(p=0,05)$ \\
\hline I & $51,1 \pm 0,04(48,0-61,0) \mathrm{N}: 57$ & 49,7 & $p>0,05$ \\
II & $68,8 \pm 0,11(56,0-86,0) \mathrm{N}: 56$ & 67,6 & $p>0,05$ \\
III & $84,7 \pm 0,06(83,0-101,0) \mathrm{N}: 54$ & 82,8 & $p>0,05$ \\
IV & $96,5 \pm 0,04(95,0-112,0) \mathrm{N}: 52$ & 95,2 & $p>0,05$ \\
V & $103,8 \pm 0,05(101,0-123,0) \mathrm{N}: 39$ & 103,5 & $p>0,05$ \\
\hline
\end{tabular}

Çizelge 2. C. turcica populasyonunun yaş-ağırlık ilişkisi (W:Ağırlık (g); SE:Standart hata).

\begin{tabular}{cccc}
\hline Yaş grubu & $W \pm S E($ min-mak $)$ & $\begin{array}{c}\text { von Bertalanffy ile } \\
\text { hesaplanan }\end{array}$ & t-testi $(p=0,05)$ \\
\hline I & $1,85 \pm 0,11(1,20-5,45) \mathrm{N}: 57$ & 0,93 & $p>0,05$ \\
II & $3,92 \pm 0,07(1,22-5,17) \mathrm{N}: 56$ & 2,42 & $p>0,05$ \\
III & $5,87 \pm 0,06(4,14-6,99) \mathrm{N}: 54$ & 4,35 & $p>0,05$ \\
IV & $7,54 \pm 0,21(6,46-11,03) \mathrm{N}: 52$ & 6,42 & $p>0,05$ \\
V & $8,95 \pm 0,16(9,74-14,32) \mathrm{N}: 39$ & 8,45 & $p>0,05$ \\
\hline
\end{tabular}

Çizelge 3. C. turcica populasyonunun boyca mutlak, oransal ve anlık büyüme değerleri.

\begin{tabular}{ccccccc}
\hline \multirow{3}{*}{ Yaş grubu } & \multicolumn{3}{c}{ Boyca büyüme } & \multicolumn{3}{c}{ Ăğrlıça büyüme } \\
\cline { 2 - 7 } & \multirow{2}{*}{ Mutlak $(\mathrm{mm})$} & $\begin{array}{c}\text { Oransal } \\
(\%)\end{array}$ & $\begin{array}{c}\text { Anlık } \\
(1 / \mathrm{y} 1)\end{array}$ & $\begin{array}{c}\text { Mutlak } \\
(\mathrm{g})\end{array}$ & $\begin{array}{c}\text { Oransal } \\
(\%)\end{array}$ & $\begin{array}{c}\text { Anlık } \\
(1 / \mathrm{y} 1)\end{array}$ \\
\hline I-II & 17,7 & 34,64 & 0,30 & 2,07 & 111,89 & 0,75 \\
II-III & 15,9 & 23,11 & 0,21 & 1,95 & 49,74 & 0,40 \\
III-IV & 11,8 & 13,93 & 0,13 & 1,67 & 28,45 & 0,25 \\
IV-V & 7,3 & 7,56 & 0,07 & 1,41 & 18,70 & 0,17 \\
\hline
\end{tabular}

Çizelge 4. C. turcica populasyonunun kondisyon faktörü değerleri ( $K F$ :Kondisyon faktörü-SE:Standart hata).

\begin{tabular}{ccc}
\hline Yaş & Balık sayısı & $K F \pm S E($ min-mak $)$ \\
\hline I & 57 & $1,37 \pm 0,09(1,24-1,45)$ \\
II & 56 & $1,20 \pm 0,04(1,16-1,62)$ \\
III & 54 & $0,97 \pm 0,02(0,62-1,46)$ \\
IV & 52 & $0,84 \pm 0,02(0,55-1,02)$ \\
V & 39 & $0,80 \pm 0,01(0,51-1,09)$ \\
\hline Toplam & 258 & $1,04 \pm 0,02(0,51-1,45)$
\end{tabular}




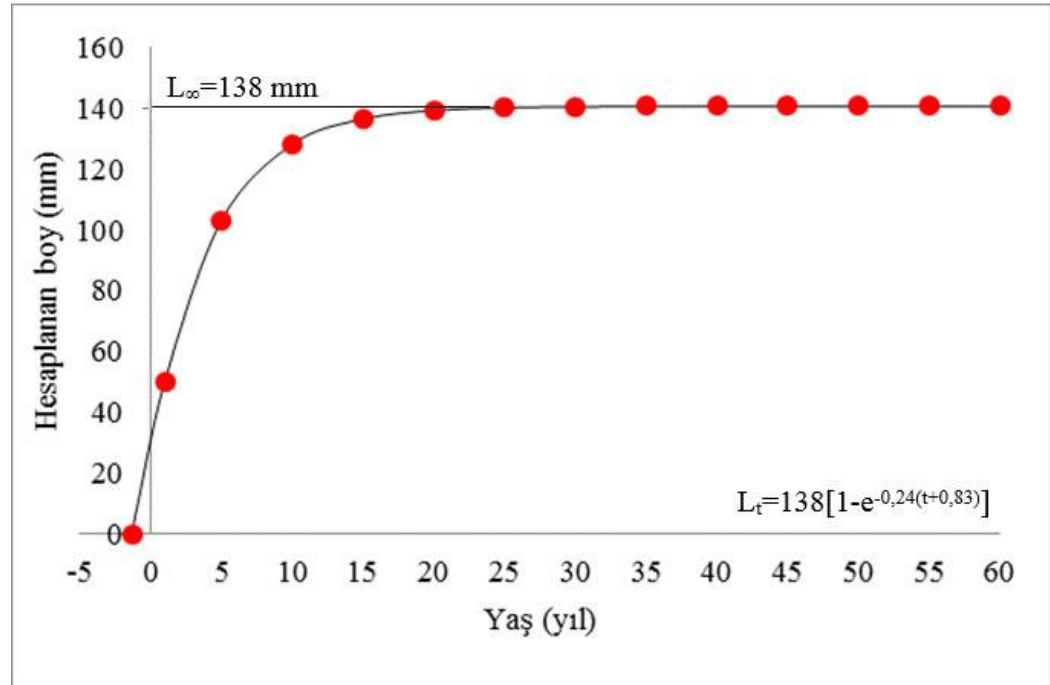

Şekil 4. C. turcica populasyonunun boyca von Bertalanffy büyüme denklemi ve eğrisi.

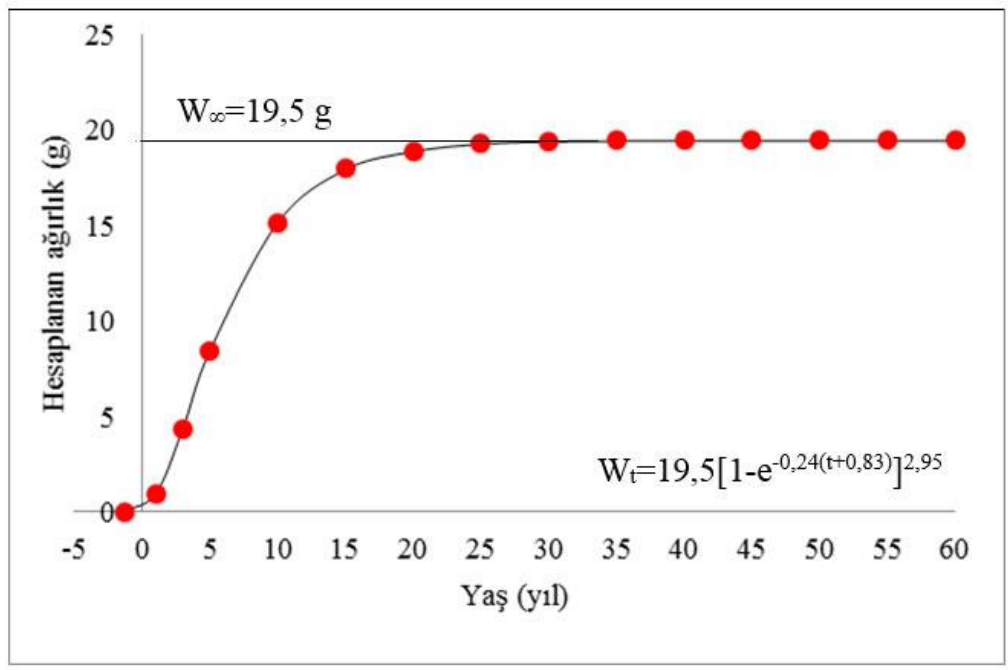

Şekil 5. C. turcica populasyonunun ağırlıkça von Bertalanffy büyüme denklemi ve eğrisi.

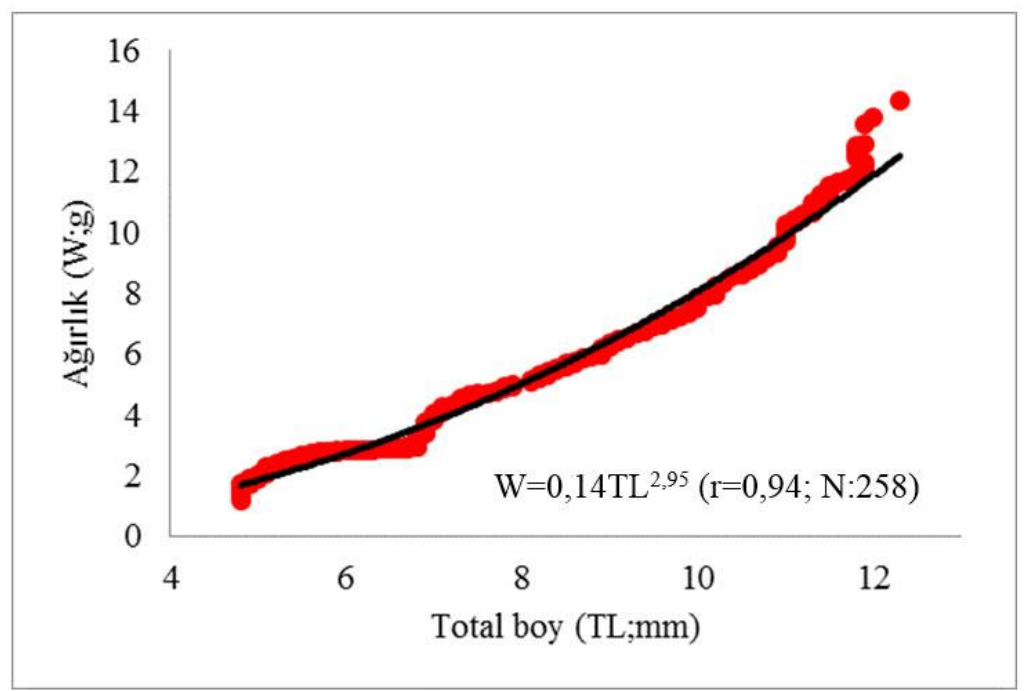

Şekil 6. C. turcica populasyonunun boy-ağırlık ilişkisi.

Heincke yöntemi ile hesaplanan yaşama oranı $S=0,71$, ölüm oranı $A=0,29$ ve anlık ölüm katsayısı

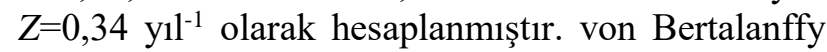

büyüme parametrelerinden yararlanılarak doğal ölüm katsayıs $M=0,30\left(\mathrm{~T}=12,51^{\circ} \mathrm{C}\right)$ ve tüm bu verilerden yararlanılarak avcılık ölüm katsayısı $F=0,04$, 
avlanmadan ileri gelen ölüm beklentisi $u=0,03$, doğal ölüm beklentisi $v=0,26$ olarak bulunmuştur.

\section{Tartışma ve Sonuç}

Cobitis türleri, akarsularda genellikle habitat çeşitliliğinin yüksek olduğu, zemin yapısı düz, kumlu, milli ve vejetasyon oranı yüksek, düşük akıntılı sularda bulunurlar (Soriguer vd. 2000). Çalışmamızdaki balık örnekleri de, zemin yapısının düz, kumlu ve milli, akıntı hızının yavaş olduğu üçüncü, dördüncü ve beşinci istasyondan yakalanmıştır. Aksu Çay1-Köprüçay Nehri’nin endemik türü olan C. turcica populasyonunun yaş, büyüme ve ölüm özelliklerini belirlemek amaciyla toplam 258 birey incelenmiş, tümünde yaş tayini yapılmış, I-V yaşları arasındaki bireylere rastlanmıştır. $C$. turcica ile yapılan diğer çalışmalarda da 0-VI yaşına kadar bireylerin bulunduğu rapor edilmiştir (Çizelge 5). Çalışmamızda 48,0-123,0 mm boylar arasındaki balıklar yakalanırken, ortalama boy $81,1 \pm 0,15 \mathrm{~mm}$ bulunmuştur. Erk'akan vd. (2013) yaptıkları çalışmada boyu 3,8-7,3 cm arasında, Kırankaya ve Ekmekçi (2014) ise 5+ yaş için boyu maksimum $103,60 \mathrm{~mm}, 6+$ yaş için $126,75 \mathrm{~mm}$ bildirirken yine farklı Cobitis türlerinin değişik habitatlarda yapılan çalışmalarında balık boyu minimum $26,3 \mathrm{~mm}$, maksimum $121 \mathrm{~mm}$ olarak tespit edilmiştir (Çizelge 5).

Erk'akan vd. (2013) Saz Gölü C. turcica populasyonunda minimum ağırlı̆g $10,4 \mathrm{~g}$, maksimum ağırlığı 3,7 g ; Patimar vd. (2011) C. cf. satunini'de 0,13-8,93 g; Mousavi-Sabet vd. (2012) C. faridpaki'de 0,4-4,2 g tespit etmiştir. Çalışmamızda ise minimum ağırlık 1,2 g, maksimum

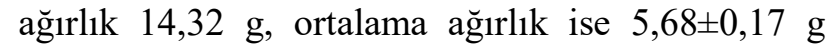
bulunmuştur. 14,32 $\mathrm{g}$ değeri diğer çalışmalarda bulunan değerlerden daha yüksektir. Büyüme türün hem genetik yapısı hem de bulunduğu habitata adaptasyon yeteneğini kapsayan çok yönlü bir durumdur. Çalışma süresince ölçülen $12,51{ }^{\circ} \mathrm{C}^{\prime}$ lik ortalama su sicaklığı gibi habitatlar arasındaki ekolojik farklılıkların da büyümede pozitif bir etki yaptığı düşünülmektedir.

Çalışmamız, aynı süreç içerisinde $C$. turcica gibi tamamı endemik olan 3 türün de araştırıldığı bir projeden özetlenmiştir. Dolayısıyla türlerin hassasiyetinden hiç biri için eşey tespiti yapılmadan tamamen arazi şartlarında boy, ağırlık değerleri ölçülmüş ve yaş tayini için pul örnekleri alınan balıklar en kısa sürede ortamlarına bırakılmıştır.

C. turcica için von Bertalanffy boy ve ağırlıkça büyüme denklemi parametreleri ilk defa hesaplanmış, farklı habitatlardaki Cobitis türlerinde hesaplanan değerler ile çalışmamızdaki $L_{\infty}, W_{\infty}, K$ ve $t_{0}$ değerleri Çizelge 6 ' da verilmiştir.

C. turcica bireylerinin boy ve ağırlık değerlerinden hesaplanan boy-ağırlık ilişkisi denklemi $W=0,14 T L^{2,95}$,korelasyon katsayısı $(r)$ ise 0,94 olarak hesaplanmış ve negatif allometrik büyüme gösterdiği belirlenmiştir. Erk'akan vd. (2013) Saz Gölü (Konya) C. turcica populasyonunda " $a$ " değerini 0,044 , " $b$ " değerini 3,322, " $r$ " değerini 0,956, Kırankaya ve Ekmekçi (2014) ise Pınarbaşı kaynağı (Gök Göl, Kozanlı) C. turcica bireylerinde "a" değerini juvenillerde $3 \times 10^{-7}$, dişilerde $1 \times 10^{-5}$, erkeklerde $8 \times 10^{-6}$, "b" değerini juvenillerde 3,69, dişilerde 2,83, erkeklerde 2,91, $r^{2}$ değerini ise juvenillerde 0,98 , dişilerde 0,92 , erkeklerde 0,81 olarak belirlemiştir. Cinsin farklı türlerine ait " $a$ ", " $b$ " ve " $r$ " değerleri Çizelge 7 'de verilmiştir. Cobitis cinsinin farklı türlerine ait çalışmalarda elde edilen sonuçlar ile bu çalışmada elde edilen sonuçlar arasındaki farkların örneklenen balıkların bulundukları ortamlar, dolayısıyla yaş, boy ve ağırlık kompozisyonları arasındaki farklılıklardan kaynaklandığı düşünülmektedir.

Araştırmada hesaplanan boyca mutlak, oransal ve anlık büyüme değerleri incelendiğinde balıkların ilk yaşlarında oransal boy ve ağırlık artışının ilerleyen yaşlara göre daha hızlı olduğu görülmektedir. Kırankaya ve Ekmekçi (2014) C. turcica populasyonunda spesifik büyümede erkek ve dişiler arasında çok az bir fark olduğunu, ilk yaşlarda büyümenin hem boyca $(\% 30-44)$ hem de ağırlıç̧a (\%94-141) çok hızlı, ilerleyen yaşlarla birlikte büyümede azalma eğilimi olduğu belirtilmiştir.

Büyümenin önemli bir göstergesi olan kondisyon faktörü değerleri I yaş için $1,37 \pm 0,09$, II yaş için $1,20 \pm 0,04$, III yaş için $0,97 \pm 0,02$, IV yaş için $0,84 \pm 0,02$, V yaş için $0,80 \pm 0,01$ ve ortalama $1,04 \pm 0,02$ olarak bulunmuştur. Kondisyon faktörünün genç yaşlarda yüksek, ileri yaşlara doğru azalma eğiliminde olduğu saptanmıştır.

Araştırmada hesaplanan anlık ölüm oranı (Z)

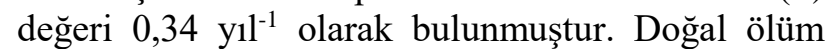

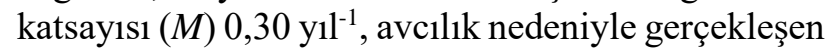

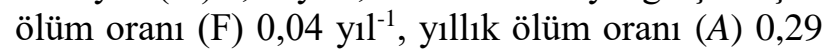
$\mathrm{y} 1^{-1}$, avlanmadan ileri gelen ölüm beklentisi (u) 0,03

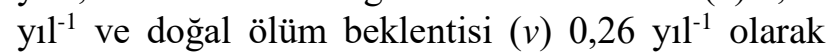
bulunmuştur. $\mathrm{Bu}$ değerlere göre Aksu Çay1Köprüçay Nehri $C$. turcica populasyonunda \%3,00'ü avc1lik ve \%26,00's1 da doğal nedenlerden olmak üzere \%29,00 oranında bir ölüm görülmektedir. Araştırmada yaşama oranı $(S)$ \% 71,00'dir. 
Çizelge 5. Cobitis cinsine ait bazı türlerin yaş ve büyüme değerleri.

\begin{tabular}{|c|c|c|c|c|c|c|c|}
\hline \multirow{2}{*}{ Türler } & \multirow{2}{*}{ Yaş aralığ 1} & \multirow[b]{2}{*}{ Eşey } & \multirow[b]{2}{*}{ Yaş } & \multicolumn{2}{|c|}{ Boy-ağırlık } & \multirow[b]{2}{*}{ ort. } & \multirow{2}{*}{ Literatür } \\
\hline & & & & $\min$. & mak. & & \\
\hline C. taenia & $0+/ 4+$ & $\mathrm{D}$ & $4+$ & & $73,1 \mathrm{~mm}$ & & Robotham (1981) \\
\hline C. taenia & $0 / \mathrm{II}$ & $\mathrm{D}+\mathrm{E}$ & & & & $61,5 \mathrm{~mm}$ & Marconato ve Rasotto (1989) \\
\hline C. merdionalis & & $\begin{array}{l}\mathrm{D} \\
\mathrm{E}\end{array}$ & & & $\begin{array}{l}121 \mathrm{~mm} \\
77 \mathrm{~mm}\end{array}$ & & Crivelli ve Lee (2000) \\
\hline C. paludica & $0+/ 5+$ & $\begin{array}{l}\mathrm{D} \\
\mathrm{E}\end{array}$ & & & $\begin{array}{l}84 \mathrm{~mm} \\
31 \mathrm{~mm}\end{array}$ & & Przybylski ve Valladolid (2000) \\
\hline C. paludica & $0+/ 4+$ & $\begin{array}{l}\mathrm{D} \\
\mathrm{E}\end{array}$ & & & $\begin{array}{l}99 \mathrm{~mm} \\
90 \mathrm{~mm}\end{array}$ & & Oliva-Paterna vd. (2002) \\
\hline C. paludica & $0+/ 7+$ & $\mathrm{D}$ & & & $115 \mathrm{~mm}$ & & Sanchez-Carmona vd. (2008) \\
\hline C. simplicispina & $\mathrm{I} / \mathrm{IV}$ & $\begin{array}{l}\mathrm{D} \\
\mathrm{E}\end{array}$ & & & & $\begin{array}{c}97 \mathrm{~mm} \\
91,8 \mathrm{~mm}\end{array}$ & Ekmekçi ve Erk'akan (2002) \\
\hline C. narentana & $0+/ 4+$ & $\begin{array}{l}\mathrm{D} \\
\mathrm{E} \\
\mathrm{D}\end{array}$ & $\begin{array}{l}4+ \\
4+\end{array}$ & $76 \mathrm{~mm}$ & $\begin{array}{c}100,4 \mathrm{~mm} \\
100,4 \mathrm{~mm} \\
80 \mathrm{~mm}\end{array}$ & & Zanella vd. (2003) \\
\hline C. cf. satunini & $1+/ 4+$ & $\begin{array}{c}E \\
D+E\end{array}$ & & $\begin{array}{c}56 \mathrm{~mm} \\
0,13 \mathrm{~g}\end{array}$ & $\begin{array}{l}60 \mathrm{~mm} \\
8,93 \mathrm{~g}\end{array}$ & & Patimar vd. (2011) \\
\hline $\begin{array}{l}\text { C. faridpaki } \\
\text { C. turcica }\end{array}$ & $1+/ 5+$ & $\begin{array}{l}\mathrm{D}+\mathrm{E} \\
\mathrm{D}+\mathrm{E}\end{array}$ & & $\begin{array}{c}26,3 \mathrm{~mm} \\
3,8 \mathrm{~cm}\end{array}$ & $\begin{array}{l}74,1 \mathrm{~mm} \\
7,3 \mathrm{~cm}\end{array}$ & & $\begin{array}{l}\text { Mousavi-Sabet vd. (2012) } \\
\text { Erk'akan vd. (2013) }\end{array}$ \\
\hline C. turcica & $0 / \mathrm{VI}$ & $\begin{array}{l}\mathrm{D} \\
\mathrm{E}\end{array}$ & $\begin{array}{l}\text { VI+ } \\
\text { V+ }\end{array}$ & & $\begin{array}{c}126,75 \mathrm{~mm} \\
103,6 \mathrm{~mm}\end{array}$ & & Kırankaya ve Ekmekçi (2014) \\
\hline C. turcica & $\mathrm{I} / \mathrm{V}$ & $\mathrm{D}+\mathrm{E}$ & & $\begin{array}{c}48 \mathrm{~mm} \\
1,2 \mathrm{~g}\end{array}$ & $\begin{array}{l}123 \mathrm{~mm} \\
14,32 \mathrm{~g}\end{array}$ & $\begin{array}{c}81,1 \mathrm{~mm} \\
5,68 \mathrm{~g}\end{array}$ & Bu çalışma \\
\hline
\end{tabular}

Çizelge 6. Cobitis cinsine ait bazı türlerin von Bertalanffy büyüme denklemi parametreleri.

\begin{tabular}{|c|c|c|c|c|c|c|}
\hline Tür & Eşey & $L_{\infty}(\mathrm{mm})$ & $K$ & $t_{0}$ & $W_{\infty}(\mathrm{g})$ & Literatür \\
\hline \multirow{2}{*}{ C. taenia } & $\mathrm{D}$ & 93 & 0,805 & & & \multirow{2}{*}{ Robotham (1981) } \\
\hline & E & 67,6 & 0,643 & & & \\
\hline \multirow{2}{*}{ C. taenia } & $\mathrm{D}$ & 126,6 & 0,32 & $-0,84$ & & \multirow{2}{*}{ Marconato ve Rasotto (1989) } \\
\hline & $\mathrm{E}$ & 76 & 0,41 & $-1,21$ & & \\
\hline \multirow{2}{*}{ C. paludica } & $\mathrm{D}$ & 91,78 & 0,239 & $-1,246$ & & \multirow{2}{*}{ Przybylski ve Valladolid (2000) } \\
\hline & $\mathrm{E}$ & 59,3 & 0,686 & $-0,616$ & & \\
\hline \multirow{2}{*}{ C. simplicispina } & $\mathrm{D}$ & 94,42 & 0,488 & $-0,458$ & & \multirow{2}{*}{ Ekmekçi ve Erk'akan (2002) } \\
\hline & E & 93,01 & 0,408 & 0,821 & & \\
\hline \multirow{2}{*}{ C. cf. satunini } & $\mathrm{D}$ & 121,65 & 0,39 & $-0,43$ & & \multirow{2}{*}{ Patimar vd. (2011) } \\
\hline & $\mathrm{E}$ & 94,95 & 0,49 & $-0,34$ & & \\
\hline C. turcica & $\mathrm{D}+\mathrm{E}$ & 138 & 0,24 & $-0,83$ & 19,5 & Bu çalışma \\
\hline
\end{tabular}

Çizelge 7. Cobitis cinsine ait bazı türlerin boy-ağırlık ilişkisi parametreleri.

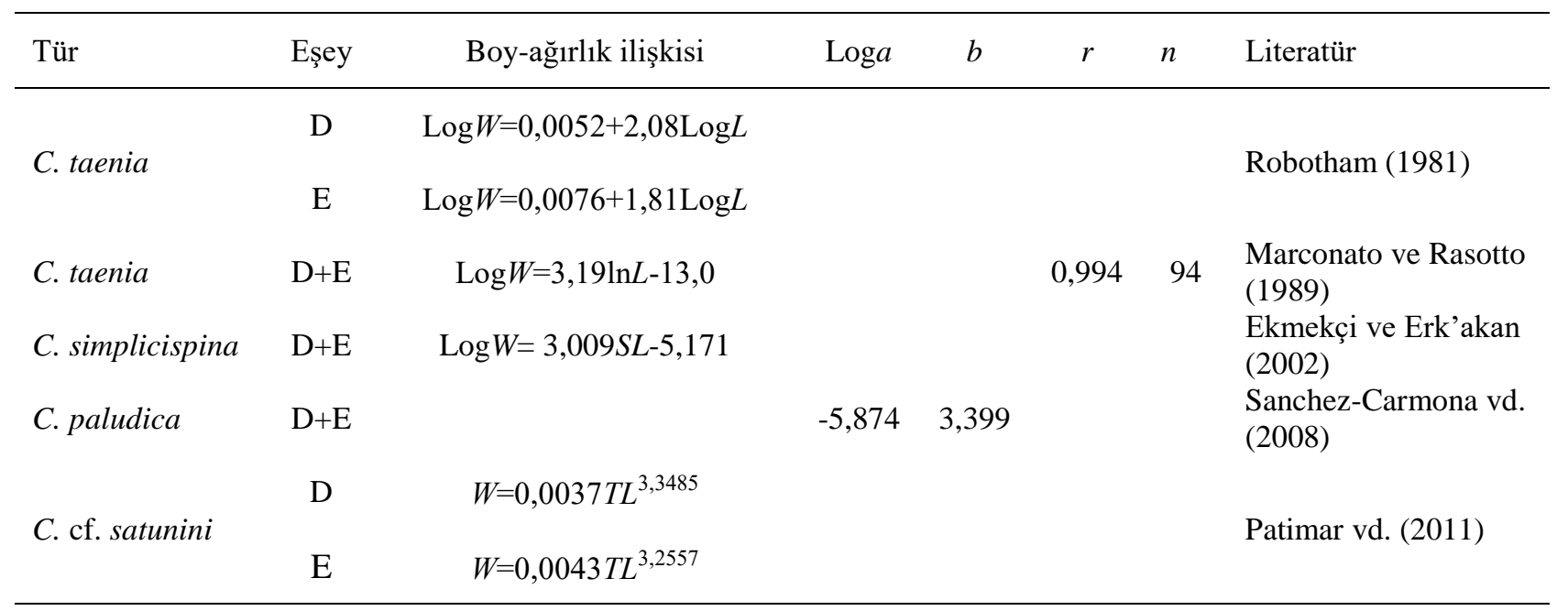


C. turcica, Orta Anadolu'nun bataklık, göl ve akarsularına yayılmış, korunması gereken endemik bir türdür. Akdeniz'deki yaşam öyküsü hakkında çok fazla bilgi olmamasına rağmen istilacı türlerin baskısı, yoğun tarımsal faaliyetlerin yapıldığı yaşam alanlarında görülen siyah nokta hastalığı (Kırankaya ve Ekmekçi, 2011) ve insan kaynaklı habitat kaybı gibi sebeplerden dolayı nesli tükenmekte olan türler arasına alınmıştır. Bu çalışmada da C. turcica örneklerinin alındığ Köprüsü) Pazarköy (Eğirdir) çıkışında, zemini kumlu, milli ve suyun kokusu rahatsız edici bir bölgedir. Köye ait atık sular ve piknik alanı olarak kullanılan alanlardan karışan çöplerin sebep olduğu kirlilik nedeniyle populasyonun tehdit altında olduğu görülmektedir. Sonuç olarak C. turcica türüne ait yaş, büyüme ve ölüm oranı bilgilerinin ayrıntılı olarak ilk defa verildiği bu çalışmanın, kısa yaşam öykülerinde tür ile ilgili muhtemel koruma ve yönetim stratejilerinin geliştirilmesi açısından faydalı olacağı düşünülmektedir.

\section{Teşekkür}

$\mathrm{Bu}$ çalışma Süleyman Demirel Üniversitesi Bilimsel Araştırma Projeleri Koordinasyon Birimi tarafından desteklenmiştir (Proje No: 1815-D-09).

\section{Kaynaklar}

Atay D, 1995. Balık üretim tesisleri ve planlaması. Ankara: AÜ Ziraat Fakültesi Yayınları: 1415, Ders Kitabi: 408, 124 s.

Bohlen J, Slechtova V, Sanda R, Kalous L, Freyhof J, Vukic J, Mrdak D. 2002. Cobitis ohridana and Barbatula zetensis in the River Moraca Basin, Montenegro:distribution, habitat, population structure and conservation needs. Paper presented at: Proceedings of the Second International Conference on Loaches of the Genus Cobitis and Related Genera; Olsztyn, Poland.

Bohlen J. 2008. Spawning Marks in spined loaches (Cobitis taenia, Cobitidae, Teleostei). Folia Zool. 57(1-2):168-171.

Coad BW, Sarıeyyüpoğlu M. 1988. Cobitis elazigensis, a new species of Cobitid Fish from Anatolia, Turkey. Jpn J Ichthyol. 34(4):426-430.

Crivelli AJ, Lee TW. 2000. Observations on the age, growth and fecundity of Cobitis meridionalis, an endemic loach of Prespa Lake (Greece). Folia Zool. 49(Suppl. I):121-127.

Crivelli AJ. 2006. Cobitis turcica. In: IUCN 2015, IUCN Red list of threatened species. Available at: http://www.iucnredlist.org (accessed on 01 June 2015).

Düzgüneş O, Kesici T, Gürbüz F. 1983. İstatistik metotları I. Ankara: AÜ Ziraat Fakültesi, Yayınları: 861, 218 s.

Ekmekçi FG, 2002. The effects of high salinity on the production of Capoeta tinca in a naturally contamined river. Turk J Zoo. 26(3):265-270.
Erk'akan F, Özeren SC, Nalbant TT. 2008. Cobitis evreni sp. nova-a new spined loach species (Cobitidae) from southern Turkey. J Fish Int. 3(4):112-114.

Erk'akan F, Innal D, Özdemir F. 2013. Length-weight relationships for ten endemic fish species of Anatolia. J App Ichthyol. 29(3):683-684. doi: 10.1111/jai.12140

Erkoyuncu İ. 1995. Balıç̧ılık biyolojisi ve populasyon dinamiği. Sinop: OMÜ Sinop Su Ürünleri Fakültesi Yayınları: 95, $265 \mathrm{~s}$.

Freyhof J, Stelbrink B, Özuluğ M, Economidis S. 2008. First record of Cobitis puncticulata from Europe with comments on its conservation status (Teleostei:Cobitidae). Folia Zool. 57(1-2):16-19.

Froese R, Pauly D. 2013. FishBase. World wide web electronic publication. Available at: http://www.fishbase.org version (accessed on 1 June 2015).

Gulland JA, Holt SJ. 1959. Estimation of growth parameters for data at unequal time intervals. J Conseil. 5(1):47-49.

Juchno D, Boron A. 2006. Age, reproduction and fecundity of the spined loach Cobitis taenia L. (Pisces, Cobitidae) from Lake Klawoj (Poland). Reprod Biol. 6(2):133-48.

Kırankaya ŞG, Ekmekçi FG. 2011. Frequency of black spot disease in Cobitis cf. turcica from Pınarbaşı Springs (Haymana, Turkey). Folia Zool. 60(4):350-354.

Kırankaya ŞG, Ekmekçi FG. 2014. Growth and reproduction of a stream population of Cobitis turcica in central Anatolia (Turkey). J Appl Ichthyol. 30(2):322-328.

doi: $10.1111 /$ jai.12375

Lagler KF. 1956. Freshwater fishery biology. W.M.C. Dubuque, Iowa: Brawn Company Publishers 421 p. Marconato A, Rasotto MB. 1989. The biology of a population of spined loach, Cobitis taenia L. Boll Zool. 56(1):73-80. doi: 10.1080/11250008909355624

Mousavi-Sabet H, Kamali A, Soltani M, Bani A, Rostami H. 2012. Age, sex ratio, spawning season, gonadosomatic index, and fecundity of Cobitis faridpaki (Actinopterygii, Cobitidae) from the Siahrud River in the southeastern Caspian Sea basin. Caspian J Env Sci. 10(1):15-23.

Nunn AD, Cowx IG, Harvey JP. 2003. Note on the ecology of spined loach in the lower River Trent, England. Fish Manag Ecol. 10(2):117-121.

Oliva-Paterna FJ, Torralva MM, Fernandez-Delgado C. 2002. Age, growth and reproduction of Cobitis paludica in a seasonal stream. J Fish Biol. 60(2):389-404. doi: 10.1006/jfbi.2001.1851

Patimar R, Amouei M, Mir-Ashrafi Langroudi SM. 2011. New data on the biology of Cobitis cf. satunini from the southern Caspian basin (northern Iran). Folia Zool. 60(4):308-314. 
Przybylski M, Valladolid M. 2000. Age and growth of Cobitis paludica in the Lozoya River (Central Spain). Folia Zool. 1-49 (Suppl.1):129-134.

Ricker WE. 1975. Computation and interpretation of biological statistics of fish populations. Bull Fish Res Board Canada. 191: 382 pp.

Robotmam PWJ. 1981. Age, growth and reproduction of a population of spined loach, Cobitis taenia (L.). Hydrobiologia. 85:129-136. doi: 10.1007/BF00006622

Sanchez-Carmona R, Encina L, Rodriguez-Ruiz A, Rodriguez-Sanchez V. 2008. Age, growth and diet of the Iberian loach, Cobitis paludica in two different environments. Folia Zool. 57(4):420-434.

Seber GAF. 1982. Estimation of animal abundance and related parameters. London: 2nd. ed. Griffin 654 p.

Smith, KG, Darwall WRT. 2006. The status and distribution of freshwater fish endemic to the Mediterranean Basin. IUCN, Gland, Switzerland and Cambridge, UK, v+ 34 pp.

Soriguer MC, Vallespin C, Gomez-Cama C, Hernando JA. 2000. Age, diet, growth and reproduction of a population of Cobitis paludica (de Buen, 1930) in the Palancar Stream (Southwest of Europe, Spain). Hydrobiologia. 436(1):51-58. doi: 10.1023/A:1026529720060

Sparre P, Ursin E, Venema C. 1989. Introduction to tropical fish stock assessment. Roma: Part 1. Manual, FAO Fisheries Technical Paper (306-1), 337 pp.

Yeğen V, Balık S, Bilçen E, Sarı HM, Uysal R, İlhan A, Bostan H. 2007. Afyonkarahisar ili akarsularında yayılış gösteren balık türleri ve dağılımları. Türk Suc Yaş Derg. 3-5(5-8):419-428.

Yeğen V. 2009. Köprüçay Nehri Yukarı Havzası (Isparta-Türkiye) balık topluluk yapısının mevsimsel ve alansal değişimi [Yüksek Lisans Tezi]. Gaziosmanpaşa Üniversitesi. 135 s.

Yurtsever N. 1984. Deneysel İstatistik Metotlar. Ankara: TC Tarım ve Köyişleri Bakanlığı Köy Hizmetleri Genel Müdürlüğü Toprak ve Gübre Araştırma Enstitüsü Müdürlüğü Yayınları: 121, Teknik Yayın: $56,623 \mathrm{~s}$.

Zanella D, Mrakovcic M, Schneider D, Mustafic P, Caleta M, Radic I. 2003. Growth of Cobitis naretana Karaman, 1928 in the Neretva River, Croatia. Folia Biol. 51 (Suppl.):155-157. 